\title{
EVOLUÇÄO CLÍNICA E LABORATORIAL DE RECÉM-NASCIDOS DE MÃES HIV POSITIVAS
}

\author{
Cristina EricoYoshimoto*, Edna Maria de Albuquerque Diniz, flávio Adolfo Costa Vaz \\ Trabalho realizado na Unidade de Cuidados Intensivos Neonatal / Instituto da Criança - \\ Hospital das Clínicas da Faculdade de Medicina da Universidade de São Paulo, São Paulo, SP
}

RESUMO - A transmissão vertical do HIV (vírus da imunodeficiência humana) tornou-se o principal alvo da profilaxia com zidovudina (AZT), utilizada durante a gestação, parto e no recémnascido (RN).

Овјетіvo. Caracterizar a evolução clínica e laboratorial de RN de mães portadoras do HIV.

Métodos. Estudo prospectivo entre 64 RN de mães portadoras do HIV classificados em dois grupos: grupo A constituído de 23 pares de mães e RN que não receberam o AZT, grupo B constituído de $4 \mathrm{I}$ pares que receberam AZT em alguma fase da profilaxia.

Resultados. A média de idade materna foi de 26,8 anos, o uso de drogas ilícitas ocorreu em 17,2\% das gestantes, 20 (3I,3\%) das gestantes apresentavam doenças. Não houve diferenças significativas entre os grupos quanto a freqüência de pré-natal, doenças maternas, antropometria de nascimento e do crescimento durante 0 seguimento. Os grupos de estudo apresentaram hemogramas e contagens de linfócitos semelhantes. A negativação sorológica ocorreu em média aos 16 meses. A transmissão vertical ocorreu em seis crianças $(9,3 \%)$ e nenhuma criança foi infectada no subgrupo que recebeu a profilaxia em todas as fases.

Conclusão. A profilaxia com AZT em todos os períodos recomendados e o seguimento a longo prazo dos RN de mães HIV positivas constitui uma das melhores estratégias para prevenção da Aids na infância.

Unitermos: Infecção. Vírus. HIV. Recém-nascidos. Zidovudina. Transmissão vertical.

\section{INTRODUÇÃO}

A transmissão vertical do HIV (vírus da imunodeficiência humana) é responsável por cerca de 80 a $90 \%$ dos casos de Aids no Brasil e no mundo.' O período em que o HIV da mãe infecta o seu concepto ainda não está claro, mas pode ser presumido através de evidências clínico-laboratoriais. A evolução clínica de crianças infectadas pelo HIV tem mostrado que cerca de 10\%-30\% destas crianças iniciam os sintomas nos primeiros meses de vida, de modo semelhante a outras infecções adquiridas intra-útero. A maioria (70\%-90\%) só apresenta sintomas após vários anos, sugerindo que a transmissão ocorre principalmente durante o parto².

Em 1994, nos Estados Unidos, foi publicado um estudo denominado ACTG 076 (Aids Clinical Trial Group), no qual foi utilizado AZT na gestante, no período intra-parto e no RN como profilaxia para transmissão vertical do HIV. Esta pesquisa demonstrou uma queda significativa da taxa de transmissão vertical de

* Correspondência:

Avenida Dr Enéas de Carvalho de Aguiar, 647 CEP: 05403-900 - São Paulo, SP
25,5\% para 8,3\%. ${ }^{3}$ No Brasil, a partir de 1995, o uso profilático de AZT tem sido recomendado e divulgado pelo Ministério da Saúde, que o preconiza a partir da $14^{a}$ semana de gestação, durante o parto e no recém-nascido (RN) por seis semanas. Embora a avaliação dessas recomendações seja um pouco prejudicada pela dificuldade de se monitorizar as várias etapas desta intervenção, os dados disponíveis têm mostrado que o número de gestantes que receberam o AZT injetável no parto em 1998 foi de apenas 2512 , enquanto 0 número de partos em gestantes HIV positivas era de 12898, ou seja, apenas 19,5\% das gestantes receberam o AZT durante o parto!

\section{Métodos}

Foram estudados prospectivamente, no período de 1994 a junho de 2000, 64 RN de mães portadoras do HIV admitidos na Unidade de Cuidados Intensivos Neonatal (UCINE) do Instituto da Criança do Hospital das Clínicas da Faculdade de Medicina da Universidade de São Paulo (HC-FMUSP) e no ambulatório desta Unidade. O estudo foi iniciado após aprovação do projeto pelo Comitê de Pesquisa e Etica do departamento de Pediatria do HCFMUSP. Durante o seguimento foram adotadas as normas preconizadas pelo Ministério da Saúde, ou seja, os RN receberam AZT durante as primeiras seis semanas de vida; Sulfametoxazol-trimetropim para a profilaxia de pneumonia por Pneumocystis carinii, a partir da sexta semana de vida e o aleitamento materno foi suspenso.

Foram consideradas crianças não infectadas pelo HIV quando apresentavam dois testes sorológicos anti-HIV negativos entre $6 \mathrm{e}$ 18 meses de idade e ausência de manifestações clínicas e laboratoriais da infecção, e infectadas quando mantinham a sorologia positiva além dos 18 meses de idade e/ou faleceram antes desta idade com doenças definidoras de infecção. $O$ grupo A foi constituído por 23 pares de mães e seus RN, que não receberam AZT em nenhum momento da profilaxia (pré-natal, parto e após o nascimento). $O$ grupo B, por 4 I crianças que de alguma forma receberam AZT, seja através do uso materno ou após o nascimento. Neste grupo, constituiu-se um subgrupo $B$ I que recebeu a profilaxia com AZT em todas as fases.

Os RN de mães portadoras do HIV foram submetidos a avaliação clínica e laboratorial no período neonatal, e posteriormente nas idades de 3, 6, 9, 12, 15, 18, 21 e 24 meses, 
após o consentimento familiar de inclusão no estudo. Em todas as consultas foi aferido peso, estatura e perímetro cefálico. As crianças foram classificadas de acordo com as categorias clínicas sugeridas pelo CDC (Centers of Disease Control) em N (assintomático), A (sintomas leves), B (sintomas moderados), e C (sintomas graves). A avaliação laboratorial constituiu-se de testes sorológicos para HIV (ELISA e WESTERN BLOT), contagem de linfócitos e hemograma. Para descrever o comportamento da antropometria ao longo do tempo foram construídos gráficos de perfis médios. A partir das variáveis peso e estatura, foram calculados percentis de peso, estatura e peso/ estatura ponderadas por sexo e idade. Estes percentis foram baseados em curvas padrão de crescimento desenvolvidas pelo National Center Health Statistics (NICHS), recomendadas pela Organização Mundial de Saúde (OMS). Foi utilizado o teste Qui-quadrado de Pearson para as comparações referentes a variáveis qualitativas. Nos casos em que as freqüências esperadas foram inferiores a 5, o teste Qui-quadrado foi substituído pelo teste exato de Fisher. $\mathrm{Na}$ análise da evolução sorológica foi utilizado o método de KaplanMeier, considerando o tempo até a negativação sorológica segundo o teste ELISA. Para a comparação das curvas utilizou-se 0 teste de Log-Rank. Foram considerados estatisticamente significantes os resultados cujos níveis descritivos foram inferiores a 0,05.

\section{Resultados}

A média de idade das mães foi de 26,8 anos. Os fatores de risco materno para a aquisição da infecção pelo HIV podem ser vistos na Tabela I. Na análise entre as variáveis entre os grupos de estudo ( $\mathrm{A}$ e B) não houve diferença estatisticamente significante entre a realização de pré-natal e doenças maternas durante 0 mesmo. Em relação à freqüência de aleitamento materno, o grupo $B$ não recebeu leite materno em nenhum momento, o qual foi prontamente abolido quando orientado. Trinta e cinco crianças nasceram através de partos normais e 29 através de cesarianas (45,3\%). A maioria dos RN era de termo $(90,6 \%)$ e apenas seis pré-termo (9,4\%), sendo adequados para a idade gestacional em $89,1 \%$ e pequenos para idade gestacional em 10,9\%. Destes 64

\begin{tabular}{lcc}
\hline \multicolumn{2}{c}{ Tabela I - Fatores de risco materno para infecção pelo HIV } \\
\cline { 1 - 2 } Fator de risco materno para HIV & $\mathbf{N}$ & \multicolumn{1}{c}{$\%$} \\
\cline { 1 - 2 } Indefinido & 22 & 34,4 \\
Usuária de drogas & 11 & 17,2 \\
Parceiro sexual anterior usuário de drogas & 10 & 15,6 \\
Parceiro sexual atual usuário de drogas & 9 & 14,0 \\
Parceiro anterior HIV+ & 9 & 14,0 \\
Transfusão & 3 & 4,8 \\
Total & 64 & 100,0 \\
\hline
\end{tabular}

Tabela 2 - Características de nascimento dos 64 RN de mães HIV positivas

\begin{tabular}{|c|c|c|}
\hline Características de nascimento & $\mathbf{N}$ & $\%$ \\
\hline \multicolumn{3}{|l|}{ Tipo de parto } \\
\hline Normal & 32 & 50,0 \\
\hline Cesárea & 29 & 45,3 \\
\hline Fórceps & 3 & 4,7 \\
\hline \multicolumn{3}{|l|}{ Idade gestacional } \\
\hline Termo & 58 & 90,6 \\
\hline Pré-termo & 6 & 9,4 \\
\hline \multicolumn{3}{|l|}{ Classificacão do RN } \\
\hline Adequado para idade gestacional & 57 & 89,1 \\
\hline Pequeno para idade gestacional & 7 & 10,9 \\
\hline \multicolumn{3}{|l|}{ Sexo } \\
\hline Feminino & 31 & 48,4 \\
\hline Masculino & 33 & 51,6 \\
\hline
\end{tabular}

Gráfico I - Representação gráfica da evolução de perfis médios dos percentis de peso para a idade

Perfil Médio

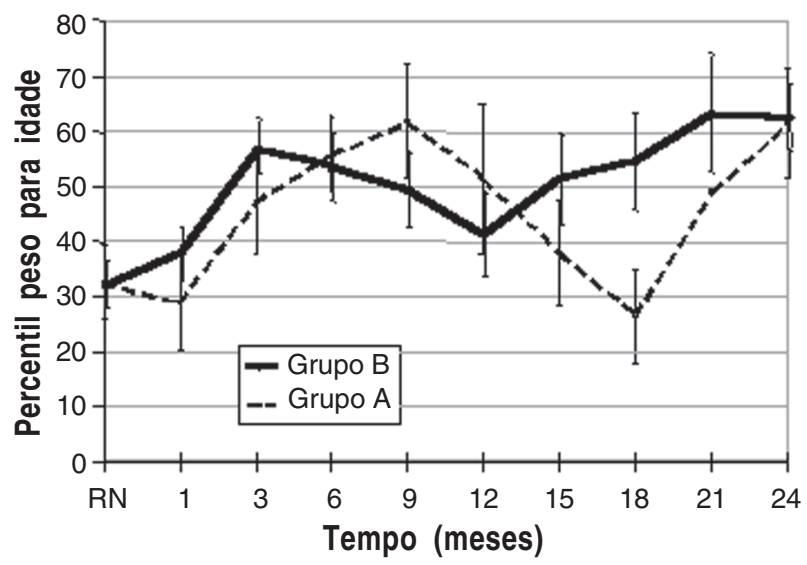

RN, $51,6 \%$ eram do sexo masculino e 48,4\% do sexo feminino. Estes RN tiveram boas condições de nascimento, o índice de Apgar de $1^{\circ}$ minuto 8 e no $5^{\circ}$ minuto de 9 (Tabela 2). Ao nascimento, a média de peso foi de $2.880 \mathrm{~g}$, estatura de $47,8 \mathrm{~cm}$ e perímetro cefálico de $33,9 \mathrm{~cm}$. Doze (I8,7\%) RN tinham baixo peso ao nascimento. Não ocorreram diferenças estatisticamente significantes em relação ao peso, estatura e perímetro cefálico de nascimento entre os grupos A e B. As curvas de crescimento não demonstraram diferenças significativas quando se analisou as curvas de crescimento por percentis de peso/idade, vistas nos Gráficos de I a 3. estatura/idade e peso/estatura e podem ser 
Gráfico 2 - Representação gráfica da evolução de perfis médios dos percentis de estatura para a idade

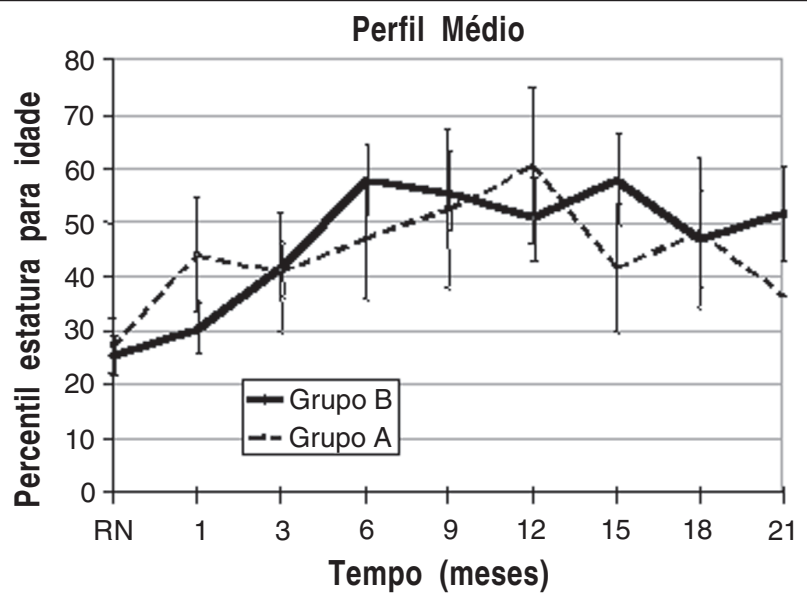

Gráfico 3 - Representação gráfica da evolução de perfis médios dos percentis de peso/estatura para idade

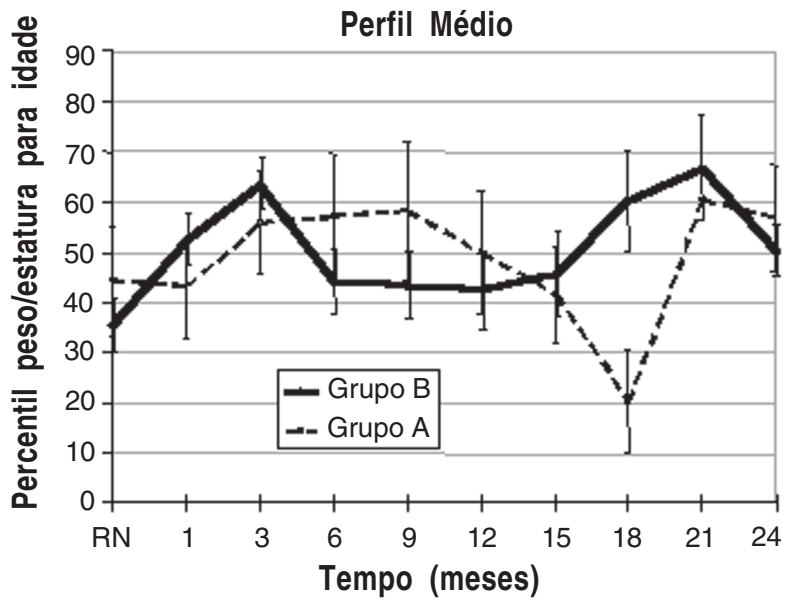

Tabela 3 - Média de idade de negativação sorológica dos RN de mães HIV positivas de acordo com os grupos $A$ e $B$

\begin{tabular}{ccc}
\hline & Idade & \multicolumn{1}{c}{} \\
& $($ meses $)$ & $(95 \%)$ \\
\cline { 2 - 3 } Grupo A & 13,6 & $\frac{(10,9 ; 16,4)}{(1,1}$ \\
Grupo B & 15,1 & $(13,3 ; 17,0)$ \\
\hline
\end{tabular}

$p=0,149$ (Teste Log Rank); IC = intervalo de confrança.

Os 64 RN foram inicialmente classificados em categorias clínicas para infecção pelo HIV de acordo com os critérios do CDC (Centers of Disease Control). Desse modo, 48 (75\%) foram categoria N, 4 (6,3\%) categoria $A, 10(15,6 \%)$ categoria $B$ e 2 (3\%) categoria $\mathrm{C}$. Durante o período neonatal e seguimento dos RN até dois anos de idade, doenças infecciosas foram as mais freqüen- tes, principalmente as de causas virais muito comuns na infância, bem como infecções de origem bacteriana (broncopneumonias, otites, infecção de trato urinário).

Durante o estudo, 15 crianças foram internadas, seis no grupo $A(26,1 \%)$ e nove no grupo $B(22,0 \%)$, não havendo diferença significativa entre os grupos de estudo ( $p=$ 0,764 ). Houve cinco óbitos, sendo três no grupo $A(20,0 \%)$, e dois no grupo $B(6,5 \%)$. Três crianças faleceram em média aos 12,6 meses de idade por doenças definidoras de Aids. As crianças apresentaram sepse e pneumonia por Candida albicans e a terceira criança evoluiu com encefalopatia necrosante sub-aguda.

A média de idade em que ocorreu a negativação sorológica foi de 16 meses. As crianças do grupo A negativaram a sorologia em média aos 13,6 meses e aquelas do grupo B aos 15, I meses. Não houve diferença estatisticamente significante entre os grupos (Tabela 3). Seis RN foram considerados infectados pelo HIV durante o seguimento. Três dessas crianças pertenciam ao grupo $A$, e três pertenciam ao grupo $B$. Chama atenção que no grupo de 21 pacientes (subgrupo B) cuja mãe e seu RN receberam AZT corretamente em todos os períodos, não houve nenhum caso de transmissão vertical. Os exames laboratoriais de hemograma e contagem de linfócitos durante o seguimento dessas crianças não demonstraram diferenças estatisticamente significantes entre os grupos do estudo (Tabelas 4 e 5).

\section{Discussão}

A Aids representa atualmente um dos mais importantes problemas de saúde pública no mundo. Em decorrência do aumento da transmissão heterossexual, tem sido cada vez maior o número de mulheres infectadas pelo HIV, conseqüentemente, ocorreu o aumento do número de crianças infectadas através da transmissão materno-infantil ${ }^{1,2}$. Nesse tipo de transmissão sexual da infecção pelo HIV, o uso de drogas injetáveis é muito freqüente. Segundo o Ministério da Saúde, $40 \%$ dos casos de transmissão vertical no Brasil estão associados ao uso de drogas injetáveis pela mãe ou por seu parceiro sexu$\mathrm{al}^{\prime}$. Em nossa pesquisa, verificamos taxas muito semelhantes a esses dados (Tabela I) como fator de risco para a aquisição do HIV nas mulheres. No Brasil, Diniz, em 1990, descreveu que cerca de $66,6 \%$ das gestantes portadoras do HIV em uma população de alto risco para doenças sexualmente transmissíveis eram usuárias de drogas injetáveis ${ }^{4}$. Mesmo após uma década nos Estados Unidos, Simpson et al., em 2000, verificaram que o principal fator de risco materno para a 


\begin{tabular}{|c|c|c|c|}
\hline \multicolumn{4}{|c|}{ Tabela 4 - Hemogramas evolutivos (valores médios) dos grupos A e B } \\
\hline & alores & (Média) Grupo A & (Média) Grupo B \\
\hline 1 & $\begin{array}{l}H B \\
L \\
P\end{array}$ & $\begin{array}{c}10,6 \\
13357 \\
206\end{array}$ & $\begin{array}{c}11,0 \\
10530 \\
403\end{array}$ \\
\hline 3 & $\begin{array}{l}H B \\
L \\
P\end{array}$ & $\begin{array}{c}10,3 \\
12205 \\
37 \mid\end{array}$ & $\begin{array}{c}10,8 \\
10667 \\
502\end{array}$ \\
\hline 6 & $\begin{array}{l}\mathrm{HB} \\
\mathrm{L} \\
\mathrm{P}\end{array}$ & $\begin{array}{c}10,6 \\
11900 \\
386 \\
\end{array}$ & $\begin{array}{l}11,1 \\
11142 \\
443 \\
\end{array}$ \\
\hline 12 & $\begin{array}{l}\mathrm{HB} \\
\mathrm{L} \\
\mathrm{P}\end{array}$ & $\begin{array}{c}10,2 \\
9860 \\
500 \\
\end{array}$ & $\begin{array}{c}10,8 \\
9549 \\
449 \\
\end{array}$ \\
\hline 18 & $\begin{array}{l}\mathrm{HB} \\
\mathrm{L} \\
\mathrm{P}\end{array}$ & $\begin{array}{c}12,3 \\
12767 \\
380 \\
\end{array}$ & $\begin{array}{r}11,8 \\
9950 \\
384 \\
\end{array}$ \\
\hline 24 & $\begin{array}{l}\mathrm{HB} \\
\mathrm{L} \\
\mathrm{P}\end{array}$ & $\begin{array}{l}11,8 \\
8950 \\
363\end{array}$ & $\begin{array}{c}11,7 \\
15000 \\
413\end{array}$ \\
\hline
\end{tabular}

$H B=$ hemoglogina $(g / d L) ; L=$ número de leucócitos $/ \mathrm{mm}^{3} ; P=$ número de plaquetas $10^{3}$ * Idade em meses

\begin{tabular}{|c|c|c|c|}
\hline \multicolumn{4}{|c|}{ Tabela 5 - Contagem de Linfócitos (CD4 e CD8) em valores médios dos grupos A e B } \\
\hline & Nalores & (Média) Grupo A & (Média) Grupo B \\
\hline 1 & $\begin{array}{c}\text { CD4 } \\
\text { CD8 } \\
\text { CD4/CD8 }\end{array}$ & $\begin{array}{c}2323 \\
1587 \\
2,1\end{array}$ & $\begin{array}{c}266 \mid \\
1113 \\
2,7\end{array}$ \\
\hline 3 & $\begin{array}{c}\text { CD4 } \\
\text { CD8 } \\
\text { CD4/CD8 }\end{array}$ & $\begin{array}{l}2657 \\
1748 \\
2,3\end{array}$ & $\begin{array}{l}2890 \\
1180 \\
2,4\end{array}$ \\
\hline 6 & $\begin{array}{c}\mathrm{CD4} \\
\mathrm{CD8} \\
\mathrm{CD} 4 / \mathrm{CD} 8\end{array}$ & $\begin{array}{l}3567 \\
1520 \\
2,7\end{array}$ & $\begin{array}{l}248 \mid \\
1355 \\
2,4 \\
\end{array}$ \\
\hline 12 & $\begin{array}{c}\text { CD4 } \\
\text { CD8 } \\
\text { CD4/CD8 }\end{array}$ & $\begin{array}{c}1758 \\
1383 \\
1,3 \\
\end{array}$ & $\begin{array}{l}2026 \\
940 \\
2,3\end{array}$ \\
\hline 24 & $\begin{array}{c}\text { CD4 } \\
\text { CD8 } \\
\text { CD4/CD8 }\end{array}$ & $\begin{array}{l}1698 \\
950 \\
2,0\end{array}$ & $\begin{array}{c}2409 \\
1345 \\
1,8\end{array}$ \\
\hline
\end{tabular}

infecção pelo HIV foi o uso de drogas injetáveis, fato constatado em cerca de $45 \%$ das gestantes infectadas pelo HIV . $^{5}$.

A realização do teste de detecção de anticorpos anti-HIV pela gestante se tornou imprescindível para se fazer o diagnóstico precoce desta infecção $0^{6}$, podendo beneficiar as mulheres e seus RN com a intervenção profilática 1,2. A realização de pré-natal pelas mães dos RN neste estudo foi encontrada em cerca de $82,8 \%$ das gestantes. $O$ exame pré-natal foi realizado no grupo A em cerca de $73,9 \%$ das gestantes e no grupo $B$ em $87,8 \%$, não se verificando diferença significativa.

Nos Estados Unidos, Lindegren et al., em 1999, em um estudo no qual foram utilizadas as recomendações do Protocolo ACTG 076, constataram que, entre 1993 a 1997, o número de mulheres testadas para - HIV antes do parto aumentou de 70\% para $94 \%$, e a proporção de mulheres e RN que receberam o AZT aumentou também de $7 \%$ para cerca de $91 \%{ }^{7}$

Em nossa pesquisa, 20 pacientes apresentaram diferentes patologias. A tuberculose esteve presente em cinco dessas gestantes, sendo esta a patologia mais freqüente (7,8 \%). A infecção simultânea entre HIV e tuberculose constitui atualmente um importante fator epidemiológico para o aumento da incidência desta última, principalmente entre a população adulta ${ }^{8}$. A progressão da doença materna tem sido associada a cargas virais elevadas e queda do número de linfócitos CD4, constituindo-se um dos principais fatores de risco materno para o aumento da transmissão vertical. ${ }^{9}$ No estudo de TESS et al., de 1999, foram analisados os diversos fatores de risco materno para a transmissão vertical do HIV no Estado de São Paulo $^{10}$. Os autores verificaram que doença materna avançada pelo HIV (Aids) foi significativamente associada à transmissão vertical do vírus, porém o mesmo não ocorreu com outras patologias como a sífilis. Apesar das doenças sexualmente transmissíveis (DST) estarem intimamente relacionadas à transmissão da infecção pelo HIV entre a população adulta, essas patologias não têm sido relatadas como significativas no aumento da transmissão vertical do HIV ${ }^{10,11}$. Em nossa casuística, DST ocorreu em cerca de 7,8\% das gestantes, destacando-se sifilis e condiloma vulvar. Três RN foram diagnosticados e tratados com sífilis congênita, tendo um apresentado neurosśfililis assintomática. O aumento recente da incidência de sífilis congênita parece relacionado à epidemia de Aids, pois a mesma representa o reflexo da incidência de sífilis adquirida nas mulheres em idade fértill'2.

O tipo de parto tem sido amplamente discutido como fator de risco para transmissão vertical do HIV; parto cesárea foi associado a menor risco para esta transmissão que o parto vaginal, ${ }^{13}$ porém há estudos que não confirmam esta diferença ${ }^{10}$.

Algumas características dos RN como sexo, idade gestacional e classificação não foram consideradas como significativas para a infeção pelo HIV 9,10,11,14.

Diversos estudos têm demonstrado que 0 leite humano pode ser associado com a transmissão vertical do HIV no período após o 
nascimento ${ }^{13,14}$. A taxa sugerida para transmissão do HIV através do aleitamento materno é de $29 \%$, e o risco adicional de transmissão do HIV através desta via, em infecções adquiridas nos períodos intra-uterino e parto, é cerca de | $4 \%(7 \%-22 \%)^{15}$.

A infecção pelo HIV não parece influenciar no crescimento fetal, apesar destas crianças terem sofrido influências negativas relacionadas ao uso freqüente de drogas ilícitas pelas mães ${ }^{16,17}$. Em nosso estudo, a média de peso de nascimento, estatura e perímetro cefálico foram semelhantes aos valores obtidos em outros estudos ${ }^{17,18}$. Não houve diferença significativa entre médias de peso, estatura e perímetro cefálico ao nascimento entre o grupo que não recebeu a profilaxia (grupo A) e o grupo que recebeu AZT (grupo B). Fato semelhante a vários estudos realizados nos Estados Unidos e Europa ${ }^{17,18,19}$, porém, entre os três e quatro meses de idade, as crianças doentes apresentaram declínios gradativos em suas respectivas curvas de crescimento e, após essa idade, houve diferenças estatisticamente significantes em suas curvas de crescimento. Ao contrário desses autores, estudos realizados na África mostraram que as crianças infectadas pelo HIV apresentavam diferenças significativas desde o nascimento com relação a peso, estatura e perímetro cefálico quando comparadas aos padrões internacionais de crescimento ${ }^{20,21,22}$.

$O$ uso de AZT em crianças infectadas pelo HIV apresenta efeito benéfico para o ganho ponderal. ${ }^{23,24}$ Mas os efeitos do AZT em crianças de mães portadoras do HIV e que atualmente recebem esta medicação profilaticamente não tinham sido verificados. No estudo ACTG 076, foram apresentados os resultados do seguimento realizado entre os RN não infectados e que tinham recebido o antiretroviral. Estas crianças foram analisadas prospectivamente até os 18 meses de idade, e não foram observadas diferenças significativas em relação ao peso, estatura e perímetro cefálico ${ }^{3}$. Mais recentemente Culnane et al., em 1999, no estudo de seguimento de 5,6 anos em crianças que participaram do ACTG 076, demonstraram que nenhum efeito adverso ocorreu em relação ao crescimento e desenvolvimento neuropsicomotor nas crianças que foram expostas à medicação profilática ${ }^{25}$.
$\mathrm{Na}$ análise clínica de nosso estudo, 64 RN foram inicialmente classificados em categorias clínicas para infecção pelo HIV de acordo com os critérios adotados pelo CDC. Desse modo, 48 (75\%) dos RN foram classificados na categoria N, 4 (6,3\%) na categoria A, 10 (I5,6\%) na categoria B e 2 (3\%) na categoria $C$. Durante o período neonatal e durante o seguimento até os dois anos de idade, verificamos que as doenças de causas infecciosas foram as mais freqüentes, principalmente as virais comuns nesta faixa etária, bem como infecções de origem bacteriana. As crianças que foram diagnosticadas como infectadas pelo HIV apresentaram maior freqüência de infecções e sempre com maior gravidade. Fato também descrito por Andiman et al.,em 1994: em um estudo prospectivo entre 104 crianças de mães HIV positivas verificaram que aquelas infectadas pelo vírus apresentaram uma maior freqüência de doenças bacterianas graves como sepse ou meningite do que as crianças não infectadas pelo $\mathrm{HIV}^{26}$. O rotineiro do sulfametoxazol-trimetropim para profilaxia da pneumonia por Pneumocystis carinii pode ter interferido em nossos resultados, pois nenhuma criança apresentou essa patologia, que ocorre freqüentemente nesta faixa etária. Vale ressaltar ainda que no grupo de crianças que recebeu a profilaxia completa com o AZT não houve nenhum óbito. Tem sido descrito que uso de terapia anti-retroviral associado a profilaxia para Pneumocystis carinii tem contribuído para diminuir o número de internações hospitalares e a morbi-mortalidade das crianças infectadas pelo $\mathrm{HIV}^{27,28}$.

A análise laboratorial de nosso estudo mostrou que os níveis médios de hemoglobina, leucócitos e plaquetas foram semeIhantes entre os grupos A e B (Tabela 4). Anemia tem sido referida como um dos efeitos adversos decorrentes do uso de AZT. Connor et al., em 1994, observaram que a anemia entre as crianças que receberam AZT era de curta duração, e reversível após a suspensão da medicaçãa ${ }^{3}$.

Com relação à contagem de linfócitos e subpopulações, não constatamos alterações significativas entre o número de linfócitos CD4 e CD8 entre os dois grupos estudados (Tabela 5). Culnane et al., em
1999, também não demonstraram diferenças quanto ao número de linfócitos CD4 e CD8 entre as crianças que utilizaram AZT e aquelas que não o usaram ${ }^{25}$.

\section{Conclusão}

Entre os 64 recém-nascidos de nossa casuística, a média de idade em que ocorreu a negativação sorológica foi de 16 meses, tendo seis RN sido considerados infectados pelo HIV durante o seguimento. Três dessas crianças pertenciam ao Grupo A e três pertenciam ao Grupo B. Chama a atenção que no grupo de 21 pacientes (subgrupo BI) cuja mãe e seus $\mathrm{RN}$ receberam $A Z T$ corretamente em todos os períodos, não houve nenhum caso de transmissão vertical. Fato este que reforça a importância da profilaxia da infecção pelo HIV através do uso de AZT na gestação, no parto e no RN. O uso de exames mais específicos são imprescindíveis para o diagnóstico e seguimento das crianças de mães portadoras de HIV, a fim de serem tomadas medidas terapêuticas o mais precoce possível naquelas que foram infectadas e minimizar a ansiedade dos familiares quanto ao diagnóstico definitivo. Muitos de nossos pacientes ficaram órfãos de pais que faleceram durante o seu seguimento ou adoeceram dificultando o acompanhamento dos mesmos. O seguimento dessas crianças é ainda importante no sentido de poder instruir os familiares quanto à gravidade da Aids e suas consequêencias. Enfatizamos que 0 uso de profilaxia com o AZT nos períodos recomendados constitui uma das melhores estratégias para a prevenção da Aids na infância.

\section{Conflito de interesse: não há.}

\section{SUMMARY}

\section{Clinical and laboratory evolution OF CHILDREN BORN TO HIV POSITIVE MOTHERS}

The vertical transmission of HIV (Human Immunodeficiency Virus) has become the main target of prophylactic Zidovudina (AZT) therapy during gestation, parturition as well as for the newborn. 
BACKGROUND. To characterize the clinical and laboratory evolution of HIV exposed children.

Methods. Prospective study of 64 HIV exposed children, classified into two groups. Group A, made up of 23 pairs of mothers and newborns, who did not receive AZT; Group B, made up of 4 I pairs, who received $A Z T$ at some stage of prophylaxis.

RESULTS. The average maternal age was 26.8 years, the use of illicit drugs occurred in $17.2 \%$ of the pregnant women, twenty (31.3\%) of the women had diseases. Between the groups there were no significant differences related to prenatal frequency of maternal illnesses, birth body dimensions and growth sequence. Both study groups presented with similarlymphocyte and blood counts. On the average, seroreversion took place at 16 months. Vertical transmission occurred in 6 children (9.3\%), none of the children in the subgroup who received prophylaxis during all phases were infected.

Conclusions. The prophylactic therapy with $A Z T$ during all the periods recommended and the long term follow-up of the HIV exposed children constitute one of the best strategies for prevention of the acquired immunodeficiency syndrome (AIDS) in infants. [Rev Assoc Med Bras 2005; 51 (2): 100-5]

KEY wORDs. Infection. Virus. HIV. Newborns. Zidovudina. Vertical transmission.

\section{RefERÊNCIAS}

I. Boletim Epidemiológico [Ministério da Saúde]. Transmissão vertical do HIV. Semana Epidemiológica 1999; jun-ago.

2. Mofenson LM. Epidemiology and determinants of vertical HIV transmission. Semin Pediatr Infect Dis 1994;5:252-65.

3. Connor EM, Sperling RS, Gelber R, Kiselev P, Scott G, O' Sullivan MJ, et al. Reduction of maternal - infant transmission of human immunodeficiency virus type | with zidovudine treatment. N Engl J Med 1994;331: 1 173-80

4. Diniz EMA. Aspectos epidemiológicos e sorológicos da síndrome de imunodeficiência adquirida em população de alto risco para doenças sexualmente transmissíveis [tese livre docência]. São Paulo: Faculdade de Medicina, Universidade de São Paulo; 1990.
5. Simpson JB, Shapiro ED, Andiman, WA. Prospective cohort study of children born to human immunodeficiency virus-infected mothers, 1985 through 1997: trends in the risk of vertical transmission, mortality and acquired immunodeficiency syndrome indicator diseases in the era before highly active antiretroviral therapy. Pediatr Infect Dis J 2000; 1 9:6 18-24.

6. Centers for Disease of Control and Prevention, Public Health Service Recommendations for human immunodeficiency virus counseling and voluntary testing for pregnant women. MMWR Morbl Mortal Wkly Rep 1995;44(77).

7. Lindegren ML, Byers RH, Thomas P, Davis SF, Caldwell B, Rogers M, et al. Trends in Perinatal Transmission of HIV/AIDS in the United States. JAMA 1999;282:53I-8.

8. Gutman LT, Moye J, Zimmer B, Tian C. Tuberculosis in human immunodeficiency virus-exposed or -infected United States children. Pediatr Infect Dis J 1994; 13:963-8.

9. European Collaborative Study. Vertical transmission of HIV-I: maternal immune status and obstetric factors. AIDS 1996; | 0: | 675-81.

10. Tess BH, Rodrigues LC, Newell M, Dunn DT, Lago TDG. Breastfeeding, genetic, obstetric and other risk factors associated with motherto-child transmission of HIV-I in São Paulo State, Brazil. AIDS 1998; 12:5 |3-20.

I I. ST. Louis ME, Kamenga M, Brown C, Nelson AM, Manzela T, Batter V, et al. Risk for perinatal HIV-I transmission according to maternal immunologic, virologic and placental factors. JAMA 1993;269:2853-9.

12. Sífilis congênita e doenças sexualmente transmissíveis dois desafios para a saúde pública. Boletim Epidemiológico [Ministério da Saúde] 1998;2(I).

13. European Collaborative Study Risk factors for mother-to-child transmission of HIV-I . Lancet 1992;339: 1007-12.

14. Blanche S, Rouzioux C, Guihard MM, Veber F, Mayaux $M$, Jacomet $C$, et al. A prospective study of infants born to women seropositive for human immunodeficiency virus type I. N Engl J Med 1989;320: 1643-8.

15. Dunn DT, Newell ML, Ades AE, Peckham, CS. Risk of human immunodeficiency virus type I transmission through breastfeeding. Lancet 1992:340:585-8.

16. Gabiano C, Tovo P, Martino M, Galli L, Gianquinto C, Loy A, et al. Mother-to-child transmission of human immunodeficiency virus typel: risk of infection and correlates of transmission. Pediatrics 1992;90:369-74.

17. Miller TL, Evans SJ, Orav EJ, Morris V, Mcintosh K, Winter HS, et al. Growth and body composition in children infected with the human immunodeficiency virus-I. Am J Clin
Nutr 1993;57:588-92.

18. European Collaborative Study. Weight, height and human immunodeficiency virus infection in young children of infected mothers. Pediatr Infect Dis J 1995; | 4:685-90.

19. Mckinney RE Jr, Robertson JWR, Duke Pediatric Aids Clinical Trials Unit. Effect of human immunodeficiency virus infection on the growth of young children. J Pediatr 1993; | 23:579-82.

20. Bulterys M, Chao A, Munyemana S, Kurawige JB, Nawrocki P, Habimana P, et al. Maternal human immunodeficiency virus I infection and intrauterine growth: a prospective cohort study in Butare, Rwanda. Pediatr Infect Dis J 1994: | 3:94-100.

21. Moye J, Rich KC, Kalish LA, Sheon AR, Diaz C, Cooper ER, et al. Natural history of somatic growth in infants born to women infected by human immunodeficiency virus. I Pediatr 1996; 1 28:58-67.

22. Lepage $P$, Msellati $P$, Hitimana D, Bazubagira A, Vangoethem C, Simonon A, et al. Growth of human immunodeficiency type I - infected and uninfected children: a prospective cohort study in Kigali, Rwanda, 1988 to 1993. Pediatr Infect Dis J 1996; 15:479-85.

23. Pizzo PA, Eddy J, Fallon J, Ballis FM, Murphy RF, Moss $\mathrm{H}$, et al. Effect of continuous intravirous infection of Zidovudine (AZT) in children with symptomatic HIV infection. N Engl J Med 1988;319:889-96.

24. Mckinney RE Jr, Maha MA, Connor EM, Flinberg J, Scott GB, Wullsohn M, et al. A multicenter trial of oral Zidovudine in children with advanced human immunodeciency virus disease. N Engl J Med 199|;324: | 0 | 8-25.

25. Culnane M, Fowler M, Lee SS, Mc Sherry G, Brady M, O' Donnel K, et al. Lack of long-term effects of in uterus exposure of zidovudine among uninfected children born to HIVinfected women. JAMA 1999;281: I 51-7.

26. Andiman WA, Mesger J, Shapiro E. Invasive bacterial infections in children born women infected with human immunodeficiency virus type I. J Pediatr 1994; 124:846-52.

27. Morris C, Araba-Owoyele L, Spector AS, Maldonado YA. Disease patterns and survival after acquired immunodeficiency syndrome diagnosis in human immunodeficiency virusinfected children. Pediatr Infect Dis J, 1996; 15:321-8

28. European Collaborative Study. Hospitalization of children born to human immunodeficiency virus-infected women in Europe. Pediatr Infect Dis J 1997; 16:1 151-6.

Artigo recebido: 18/1 I/03

Aceito para publicação: 23/09/04 